\title{
Implementasi PPK Berbasis Kelas Melalui Literasi Pada Masa Pandemi Covid 19 Di SMP Muhammadiyah 1 Malang
}

\author{
${ }^{1}$ Sri Wahyuni, ${ }^{1}$ Iin Hindun, ${ }^{2}$ Yanur Setyaningrum, ${ }^{2}$ Masrudi
}

${ }^{1}$ Prodi Pendidikan Biologi, FKIP, Universitas Muhammadiyah Malang, Jl. Raya Tlogomas No. 246, Malang, Indonesia 65144

${ }^{2}$ SMP Muhammadiyah 1 Kota Malang, Jl. Slamet Riadi No. 134, Malang, Indonesia

\section{Email Korespondensi: swahyuni48@gmail.com}

\begin{tabular}{|c|c|}
\hline Article Info & Abstract \\
\hline $\begin{array}{l}\text { Article History } \\
\text { Received: } 2020-10-22 \\
\text { Revised: } 2020-10-29 \\
\text { Published: } 2020-10-30\end{array}$ & \multirow[b]{2}{*}{$\begin{array}{l}\text { Implementation of Class-Based PPK through Literacy During the Covid } 19 \\
\text { Pandemic at SMP Muhammadiyah } 1 \text { Malang. SMP Muhammadiyah } 01 \\
\text { Malang has implemented the Class-based Character Education Strengthening } \\
\text { Program (PPK), but in its implementation it still needs to be improved, because } \\
\text { it has not focused on literacy variations in learning. One of the ways to } \\
\text { improve the implementation of KDP is through literacy. Literacy development } \\
\text { through the Class-Based KDP approach during the Covid } 19 \text { pandemic was } \\
\text { carried out through online learning. This service aims to improve the } \\
\text { implementation of PPK with the literacy movement at SMP Muhammadiyah } 1 \\
\text { Malang. The service was carried out by means of training and mentoring } \\
\text { methods. which refers to a situation analysis of mutually agreed upon } \\
\text { programs. The target of this service includes the principal, } 20 \text { teachers of SMP } \\
\text { Muhammadiyah } 1 \text { Malang. The result of this service is that } 80 \% \text { of the teachers } \\
\text { can analyze the KDP concept and develop PPK-integrated lesson plans } \\
\text { through the literacy movement, 65\% of the teachers can carry out learning } \\
\text { using PPK integrated lesson plans through the online literacy activities. The } \\
\text { conclusion of this service activity is the increased insight and competence of } \\
\text { teachers in compiling PPK-based lesson plans through literacy movements, } \\
\text { increasing teacher skills in implementing classroom learning according to the } \\
2013 \text { Curriculum which implements KDP through more varied literacy } \\
\text { movements including literacy, numerical literacy, scientific literacy, literacy } \\
\text { ICT and cultural literacy. }\end{array}$} \\
\hline $\begin{array}{l}\text { Keywords } \\
\text { Class based character; } \\
\text { Literacy activities; } \\
\text { Online learning }\end{array}$ & \\
\hline Informasi Artikel & Abstrak \\
\hline $\begin{array}{l}\text { Sejarah Artikel } \\
\text { Diterima: } 22-10-2020 \\
\text { Direvisi: } 29-10-2020 \\
\text { Dipublikasi: } 30-10-202\end{array}$ & \multirow{2}{*}{$\begin{array}{l}\text { SMP Muhammadiyah 01 Malang sudah melaksanakan Program Penguatan } \\
\text { Pendidikan Karakter (PPK), berbasis kelas, tetapi dalam pelaksanaannya masih } \\
\text { perlu ditingkatkan, karena belum memfokuskan pada variasi literasi dalam } \\
\text { pembelajarannya. Salah satu cara untuk meningkatkan penerapan PPK adalah } \\
\text { melalui literasi. Pengembangan literasi melalui pendekatan PPK Berbasis Kelas } \\
\text { di masa pandemic Covid } 19 \text { ini dilakukan melalui pembelajaran Daring. } \\
\text { Pengabdian ini bertujuan untuk meningkatkan penerapan PPK dengan gerakan } \\
\text { literasi di SMP Muhammadiyah } 1 \text { Malang. Pengabdian dilakukan dengan } \\
\text { metode pelatihan dan pendampingan. yang mengacu pada analisis situasi } \\
\text { program-program yang telah disepakati bersama. Sasaran pengabdian ini } \\
\text { meliputi Kepala Sekolah, } 20 \text { guru SMP Muhammadiyah } 1 \text { Malang Hasil } \\
\text { pengabdian ini adalah guru } 80 \% \text { dapat menganalisis konsep PPK dan } \\
\text { mengembangkan RPP yang terintegrasi PPK melalui gerakan literasi, } 65 \% \text { guru } \\
\text { dapat melaksanakan pembelajaran menggunakan RPP yang terintegrasi PPK } \\
\text { melalui gerakan literasi secara daring. Kesimpulan kegiatan pengabdian ini } \\
\text { adalah meningkatnya wawasan dan kompetensi guru dalam menyusun RPP } \\
\text { berbasis PPK melalui gerakan literasi, meningkatnya ketrampilan guru dalam } \\
\text { melaksanakan pembelajaran di kelas sesuai Kurikulum } 2013 \text { yang menerapkan }\end{array}$} \\
\hline $\begin{array}{l}\text { Kata kunci } \\
\text { Gerakan Literasi, } \\
\text { Pembelajaran } \\
\text { Daring, PPK } \\
\text { berbasis kelas }\end{array}$ & \\
\hline
\end{tabular}


PPK melalui gerakan literasi lebih bervariasi meliputi literasi baca tulis, literasi numerik, literasi science, literasi ICT dan literasi budaya.

Sitasi: Wahyuni S., Hindun I., Setyaningrum Y., \& Masrudin (2020) Implementasi PPK Berbasis Kelas Melalui Literasi Pada Masa Pandemi Covid 19 Di SMP Muhammadiyah 1 Malang. Sasambo: Jurnal Abdimas (Journal of Community Service). 2(3),196-208 DOI 10.36312/sasambo.v2i3.315

\section{PENDAHULUAN}

Karakter merupakan cerminan dari kepribadian secara utuh dari seseorang: mentalitas, sikap dan perilaku. Pendidikan karakter berperan penting dalam Pembinaan moral agar peserta didik dapat memahami dan memperhatikan serta melakukan nilai-nilai etika dan tingkah laku yang baik untuk kehidupan pribadi dan bermasyarakat. (Dinas Pendidikan, 2017; Isnaini, 2018; Paramansyah, Endaryono, \&Djuharton, 2019). Oleh karena itu Implementasi Penguatan Pendidikan Karakter (PPK) selalu harus dikembangkan baik di lingkungan keluarga, sekolah, maupun masyarakat. Salah satu cara untuk meningkatkan penerapan PPK di sekolah dengan gerakan literasi (Kemdikbud, 2016a). Literasi perlu dikembangkan dan diintegrasikan dalam kegiatan pembelajaran. Pengembangan literasi melalui pendekatan Penguatan Pendidikan Karakter (PPK) Berbasis Kelas dilakukan melalui pengembangan metode pembelajaran, pengelolaan kelas (pengelolaan peserta didik dan penciptaan lingkungan fisik kelas kaya teks) dan pengintegrasian kegiatan literasi dalam RPP Kurikulum 2013 (Kementerian Pendidikan dan Kebudayaan, 2016a; Zaenab, 2020)

Menurut Kementerian Pendidikan dan Kebudayaan (2016b); (2016c), ada tiga pilar dalam menghadapi perubahan jaman yaitu literasi, kompetensi dan karakter. Literasi akan berkembang dengan baik apabila guru memahami literasi dalam arti luas, seperti pengenalan akan jenis-jenis literasi, jenis-jenis teks, dan pemanfaatan teks multimoda dalam pembelajaran. Dimensi literasi ini perlu diintegrasikan secara utuh dalam keseluruhan kegiatan pembelajaran mulai dari kegiatan pembukaan sampai kegiatan penutup sehingga pembelajaran menjadi pengalaman yang menyenangkan dan menantang pemikiran kritis dan kreatif dari guru dan peserta didik.

Siswa atau pesera didik yang hidup pada abad -21 harus menguasai keilmuan, berketerampilan metakognitif,mampu berpikir kritis dan kreatif, serta bisa berkomunikasi atau berkolaborasi yang efektif (Greenstein,2012; Sugiyarti, 2018). Peserta didik memerlukan 16 keterampilan agar mampu bertahan di abad 21, yakni literasi dasar (bagaimana peserta didik menerapkan keterampilan berliterasi untuk kehidupan sehari-hari), kompetensi (bagaimana peserta didik menyikapi tantangan yang kompleks), dan karakter (bagaimana peserta didik menyikapi perubahan lingkungan mereka).

Menurut framework 21-st Century Education yang dikembangkan oleh World Economic Forum (WEF), ada 16 keterampilan penting yang perlu disiapkan dan dimiliki anak-anak agar mereka survive dan berhasil masa sekarang. Enam belas keterampilan itu terbagi menjadi 3 kelompok yaitu literasi dasar (foundational literacies) kompetensi (competencies), dan pendidikan karakter (character qualities). Untuk menyukseskan pembangunan Indonesia di abad ke-21, masyarakat Indonesia harus menguasai enam literasi dasar, yaitu (1) literasi bahasa, (2) literasi numerasi, (3) literasi sains, (4) literasi digital, (5) literasi finansial, serta (6) literasi budaya dan kewargaan. Kemampuan literasi ini juga harus diimbangi dengan menumbuhkembangkan kompetensi yang meliputi kemampuan berpikir kritis/memecahkan masalah, kreativitas, komunikasi, dan kolaborasi (Kemdikbud, 2017a). 
Pembelajaran yang kontekstual dan menarik perlu menghubungkan bahan pembelajaran dengan latar belakang sosiokultural dan pengalaman peserta sehingga mampu menumbuhkan minat pada diri peserta didik untuk belajar dan ingin tahu lebih banyak lagi. Topik pembelajaran seharusnya dapat menuntun peserta untuk menggali informasi lewat sumber belajar yang lain. Selain itu, pembelajaran yang kaya literasi mampu menumbuhkan daya nalar, kemampuan berpikir kritis, analitis, dan reflektif peserta (Kementerian Pendidikan dan Kebudayaan, 2016d, Dewayani, 2017).

Literasi adalah kecakapan fundamental yang membekali peserta didik dengan kemampuan memilih, menganalisis informasi dengan kritis serta menggunakannya untuk mengambil keputusan dalam kehidupan. Pelaksanaan Kebijakan Pendidikan dalam Masa Darurat Corona Virus Disease, menuntut pendidik untuk melakukan sebuah inovasi pembelajaran, yaitu pembelajaran self directed learning berbasis literasi digital. Kecakapan literasi membangun kecakapan hidup yang dapat meningkatkan ketahanan peserta didik untuk melalui masa pandemic (Dewayani, 2020; Hanik, 2020). Menurut Sutrisna, et.al (2019); Supiandi, (2016) mengemukakan bahwa Literasi Sekolah pada konteks Gerakan Literasi Sekolah.yaitu keahlian mengakses, menguasai, dan memakai sesuatu proses cerdas melintsi berbagai kegiatan, seperti membaca, menyimak, menulis dan berbicara. (Mitasari \& Utami, 2017) Kompetensi literasi memfokuskan pelajar agar bisa melakukan analisis secara kritis, seperti membuat wawancara, observasi lingkungan, menulis laporan, dan melakukan pengamatan langsung

Survei tentang literasi yang dilakukan Central Connecticut State University pada tahun 2016 di New Britain, Conn, Amerika Serikat, misalnya, menempatkan Indonesia dalam posisi cukup memprihatinkan, yaitu urutan ke-60 dari 61 negara. Sementara Sementara itu, hasil survei Progamme for International Student Assessment (PISA) 2015 yang diumumkan pada awal Desember 2016 menunjukkan hasil yang tidak jauh berbeda. Hasil survei tersebut mengisyaratkan bahwa literasi bangsa Indonesia merupakan persoalan yang harus ditangani dengan serius ( Kemdikbud 2017a).

Pada saat ini pelaksanaan pelaksanaan PPK di sekolah, terutama PPK berbasis kelas masih terus diupayakan. Demikian juga pada sekolah Muhammadiyah. Literasi akan berkembang dengan baik bila guru memahami literasi dalam arti luas, seperti pengenalan akan jenis-jenis literasi, jenis-jenis teks, dan pemanfaatan teks multimodia dalam pembelajaran. Dimensi literasi ini perlu diintegrasikan secara utuh dalam keseluruhan kegiatan pembelajaran mulai dari kegiatan pembukaan sampai kegiatan penutup sehingga pembelajaran menjadi pengalaman yang menyenangkan dan menantang pemikiran kritis dan kreatif dari guru dan peserta didik.

SMP Muhammadiyah 1 Malang, sudah menerapkan pendidikan karakter dalam proses pembelajaran di dalam maupun di dalam kelas. Namun dalam pelaksanaannya masih belum terintegrasi dengan gerakan literasi. Untuk itu perlu perlu dilaksanakan pelatihan penguatan pendidikan karakter, yang dilanjutkan dengan pendampingan dalam perencanaan dan pelaksanaan penguatan pendidikan karakter melalui kegiatan literasi. Materi yang disajikan terutama menekankan pada peningkatan keterampilan mengelola pembelajaran dengan strategi literasi untuk meningkatkan kecakapan literasi siswa dan mengembangkan keterampilan abad ke-21, termasuk keterampilan berpikir tingkat tinggi. Keterampilan berpikir tingkat tinggi (keterampilan abad ke-21) merupakan salah satu kompetensi capaian implementasi Kurikulum 2013.

Pengabdian yang telah dilakukan sebelumnya di SMP Muhammadiyah 01 Malang adalah pada tahun 2107 telah diaksanakan Pengabdian berupa "Pendampingan Pembuatan Asesmen Awal dan Pembuatan RTL PPK, hasilnya berupa tersusunnya dokumen asesmen 
awal PPK dan Dokumen Rencana Tindak Lanjut PPK. Selanjutnya Tahun 2018 telah dilakukan Pendampingan pengintegrasian PPK dalam Kurikulum 2013, Hasilnya berupa Dokumen Perencanaan dan pelaksanaan integrasi PPK dalam Kurilulum 2013 ( Wahyuni, et. al, 2017).

Pelaksanaan PPK ini akan dipercepat dengan gerakan literasi. Untuk itu selanjutnya pada tahun 2020 perlu dilakukan pendampingan pelasanaan PPK melalui literasi di lingkungan Sekolah Menengah Pertama Muhammadiyah 01 Kota Malang.

Pendampingan ini bertujuan untuk meningkatkan penerapan PPK dengan gerakan literasi di SMP Muhammadiyah 1 Malang. Melalui gerakan literasi ini, diharapkan dapat berkontribusi dalam peningkatan wawasan dan kompetensi guru dalam mengembangkan RPP berbasis PPK melalui gerakan literasi, Peningkatan keterampilan guru dalam merencanakan dan melaksanakan pembelajaran sesuai Kurikulum 2013 yang menerapkan PPK melalui gerakan literasi, yang pada akhirnya berkontribusi pada ketercapaian siswa yang diharapkan pada kurikulum 2013, yaitu peningkatan karakter melalui gerakan literasi.

\section{METODE PELAKSANAAN}

Program pengabdian dilaksanakan di SMP Muhammadiyah 1 Malang pada Bulan JuliOktober 2020. Pelaksanaan pendampingan menggunakan metode pelatihan dan pendampingan yang mengacu pada analisis situasi program-program yang telah disepakati bersama. Sasaran pengabdian ini meliputi Kepala Sekolah, 20 guru SMP Muhammadiyah 1 Malang. Teknik pengumpulan data melalui observasi dan dokumentasi sedangkan teknik analisis data adalah diskriptif. Metode yang ditawarkan dalam pelaksanaan pengabdian masyarakat ini berkaitan dengan permasalahan mitra adalah:

1. Pelatihan Penguatan Pendidikan Karakter (PPK) melalui gerakan litersi

2. Pendampingan dalam perencanaan Penguatan Pendidikan Karakter (PPK) melalui gerakan literasi

3. Pendampingan dalam mempraktikkan Penguatan Pendidikan Karakter (PPK) melalui gerakan literasi

Solusi dapat digambar dalam kerangka pemecahan masalah sebagai berikut.

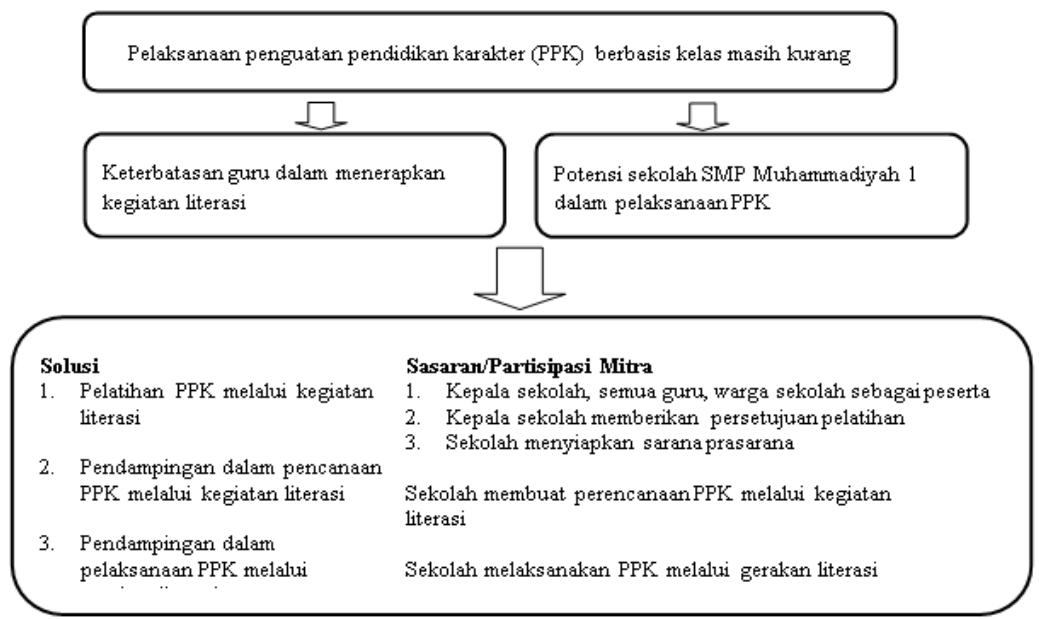

Gambar 1 : Kerangka Pemecahan Masalah

Target masing-masing kegiatan dapat dilihat pada kompetensi dasar dan indikator ketercapaian berikut ini.

Tabel 1: Target masing-masing Kegiatan, KD dan Indikator Ketercapaian

\begin{tabular}{clll}
\hline No & \multicolumn{1}{c}{ Kegiatan } & \multicolumn{1}{c}{ Kompetensi Dasar } & \multicolumn{1}{c}{ Indikator Ketercapaian } \\
\hline 1. & Pelatihan penguatan & Menguasai konsep & Menganalisis konsep PPK \\
& pendidikan karakter (PPK) & PPK melalui gerakan & melalui gerakan literasi
\end{tabular}




\begin{tabular}{|c|c|c|c|}
\hline & melalui gerakan literasi & literasi & \\
\hline 2. & $\begin{array}{l}\text { Pendampingan } \\
\text { perencanaan PPK melalui } \\
\text { gerakan literasi }\end{array}$ & $\begin{array}{l}\text { Mengembangkan } \\
\text { perencanaan PPK } \\
\text { melalui gerakan literasi }\end{array}$ & $\begin{array}{l}\text { Mengembangkan } \\
\text { perencanaan PPK melalui } \\
\text { gerakan literasi }\end{array}$ \\
\hline 3. & $\begin{array}{l}\text { Pendampingan } \\
\text { pelaksanaan PPK melalui } \\
\text { gerakan literasi }\end{array}$ & $\begin{array}{l}\text { Melaksanakan PPK } \\
\text { melalui gerakan literasi }\end{array}$ & $\begin{array}{l}\text { Melaksanakan PPK melalui } \\
\text { gerakan literasi }\end{array}$ \\
\hline
\end{tabular}

\section{HASIL DAN PEMBAHASAN}

Hasil pendampingan menunjukkan bahwa kepala sekolah dan guru-guru SMP Muhammadiyah 1 Malang memberikan dukungan terhadap program pelaksanaan PPK melalui gerakan literasi dari tim pelaksana FKIP UMM. Pelaksanaan Kegiatan Pengabdian di SMP Muhammadiyah 01 Kota Malang, telah dilaksanakan dengan baik, yang meliputi kegiatan pelatihan dan pendampingan.

Tabel 1 : Kegiatan Pelatihan dan Pendampingan Pelaksanaan PPK melalui Literasi di SMP Muhammadiyah 1 Malang

\begin{tabular}{llll}
\hline No & KEGIATAN & \multicolumn{3}{c}{ KETERCAPAIAN } \\
\hline 1 & Pelatihan penguatan pendidikan & 16 guru (80\%) aktif mengikuti dapat \\
& karakter (PPK) melalui gerakan & menganalisis konsep PPK melalui gerakan \\
& literasi & literasi \\
2 & Pendampingan perencanaan PPK & 16 guru $(80 \%)$ dapat mengembangkan RPP \\
& melalui gerakan literasi & yang terintegrasi PPK melalui gerakan literasi \\
3 & Pendampingan pelaksanaan PPK & 13 guru (65\%) dapat melaksanakan \\
& melalui gerakan literasi & pembelajaran PPK melalui gerakan literasi \\
\hline
\end{tabular}

\section{Pelatihan penguatan pendidikan karakter (PPK) melalui gerakan literasi}

Pelatihan Penguatan Pendidikan Karakter (PPK) melalui gerakan literasi diikuti oleh semua guru SMP Muhammadiyah 01 Malang kelas VII dan kelas VIII beserta kepala sekolah, Dari Pelatihan ini, guru guru SMP Muhammadiyah 01 Kota Malang diharapkan mampu menguasai konsep Penguatan Pendidikan Karakter (PPK) melalui gerakan literasi. Materi Pelatihan meliputi : Ketrampilan yang dibutuhkan pada abad 21, Penerapan PPK melalui literasi, Jenis-jenis literasi, Gelakan Literasi Sekolah, Pengintegrasian Literasi dalam Kurikulum 2013. Dalam kegiatan pelatihan ini dihadiri oleh tim pengabdian UMM dan guruguru SMP Muhammadiyah Guru-guru sangat antusias mengikuti kegiatan ini, terbukti dengan banyaknya peserta yang hadir. Setelah kegiatan selesai, peserta diminta untuk mendesain RPP yang terintegrasi PPK dan presentasi Rencana Tindak Lanjut.
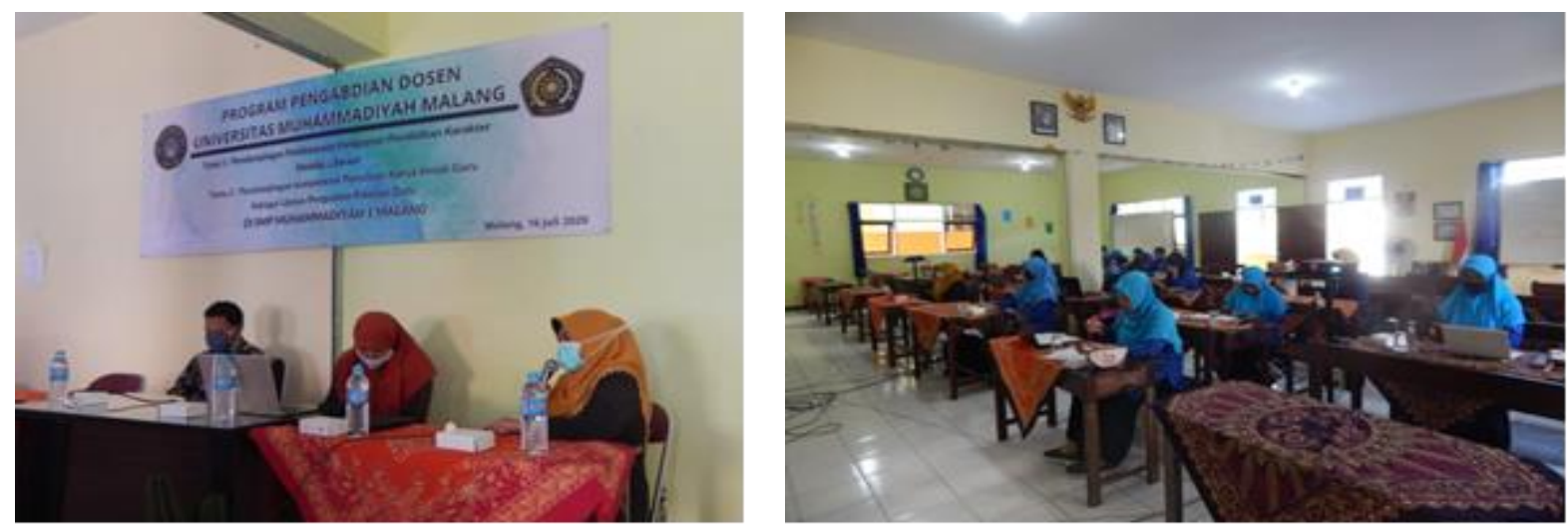

Gambar : 1. Narasumber/Pengabdi sedang memberikan materi Pelatihan PPK, 2. Pelaksanaan Pelatihan PPK melalui gerakan literasi 


\section{Pendampingan perencanaan PPK melalui gerakan literasi}

Kegiatan pendampingan dilaksanakan selama kurang lebih 4 bulan, berupa kegiatan ini beupa pendampingan penyusunan RPP K13 yang terintegrasi PPK melalui gerakan literasi. Pendampingan dilaksanakan melalui kegiatan diskusi dan konsultasi secara daring melalui telfon atau WA group. Hasil dari kegiatan pendampingan berupa RPP berdasarkan kurikulum 2013 yang terintegrasi PPK dan Literasi pada materi IPA kelas VII dan Kelas VIII

\section{Pendampingan pelaksanaan PPK melalui gerakan literasi}

Setelah RPP yang mengintegrasikan nilai-nilai PPK dan literasi dalam kurikulum 2013 terbentuk, dilanjutkan dengan pelaksanaan pembelajaran sesuai RPP yang telah disusun yaitu (1) melaksanakan metode pembelajaran literasi untuk PPK, (2) menggunakan media pembelajaran literasi untuk PPK, dan (3) melaksanakan penilaian PPK dengan menggunakan literasi. Dalam kegiatan ini partisipasi mitra adalah guru-guru yang telah menyusun RPP akan melaksanakan PPK melalui gerakan literasi. Dalam pelaksanaan pembelajaran guru dibekali dengan bagaimana pengelolaan kelas yang baik untuk mengembangkan literasi.

Contoh Kegiatan Pembelajaran Kelas VIII secara Daring

KD 3.3: Menjelaskan konsep usaha, pesawat sederhana, dan penerapannya kehidupan sehari-hari termasuk kerja otot pada struktur rangka manusia

KD 4.3: Menyajikan hasil penyelidikan atau pemecahan masalah tentang manfaat penggunaan pesawat sederhana dalam kehidupan sehari-hari

Mata pelajaran IPA, Materi: Usaha dan Energi. Kelas VIII SMP Muhammadiyah 01 Malang Alokasi Waktu : 3x40 menit Semester Ganjil

1. Tujuan Pembelajaran

Selama dan setelah mengikuti proses pembelajaran secara ini secara daring, peserta didik dapat

a) Menjelaskan konsep energi, dengan benar

b) Menjelaskan konsep usaha, dengan benar

c) Menganalisis keterkaitan hubungan energy dan Usaha

d) Menghitung besaran usaha dengan teliti

e) Menerapkan usaha dalam kehidupan sehari-hari

Media dan Alat Pembelajaran

$\begin{array}{ll}\text { Alat } & : \text { Laptop, Android/ HP } \\ \text { Media Pembelajran } & : \text { Google Classroom }\end{array}$

Tabel 2. Langkah Kegiatan Pembelajaran (Bagian awal/pembukaan)

\begin{tabular}{lllll} 
No Jam & Isi & Keterangan & Literasi \\
\hline 1 & 08.41 & Aktifitas guru & "Assalaamu'alaikum wr. wb. Halo.... apa & Budaya \\
& membuka & kabar anak HEBAT, lama tak jumpo nich. & Baca tulis \\
& pelajaran & semoga semua yang ada di kelas ini diberikan ICT \\
& dengan Salam; & kesehatan oleh Allah SWT. Oh ya ibadah & \\
& menanyakan & wajib dan sunnah tetap rutin dikerjakan ya. \\
& kabar dan doa & Anak-anak pada pertemuan hari Senin, 31 \\
& harapan: pesan & Agustus ini kita belajar tentang Usaha, namun \\
& sikap religius, & sebelumnya seperti biasa kalian absen dulu ya \\
& $; \quad$ cek & (sebagai penilaian sikap kalian di raport) \\
& kehadiran; & gaesss... perlu diperhatikan di tengah \\
& motivasi; & pelajaran dan akhir nanti saya absen lagi lho & \\
& Sikap siswa & ya (ketika saya panggil tidak dijawab berarti \\
& ::Tanggung & kalian saya anggap keluar pelajaran. kalau ada & \\
& &
\end{tabular}


jawab, pertanyaan, tanggapan, dll bisa diketik di disipin aturan kolom komentar. keaktivan kalian dalam belajar, berkomentar baik bertanya maupun menjawab akan menjadi penilaian kalian di raport. Oke selamat belajar dan TETAP SEMANGAT Wassalaamu'alaikum wr. wb."

09.07 Apersepasi Materi: video tentang lari -lari mendukung Menyampaika materi energi gerak

ICT

Baca tulis $\mathrm{n}$ video diikuti pertanyaan: apa pendapat kalian?

Sikap siswa : "Baiklah anak-anak, coba perhatikan video di Keingintahuan bawah silahkan berkomentar kalau memang inisiatif

8.40- Aktivitas

9.17 siswa
https://drive.google.com/file/d/1TSzFLABKx Numerik 16GINmnAlIAP2zvJjQUHggw/view?usp=dri Sains vesdk ada yang dikomentari”.

Menanggapi pertanyaan guru, melaksanakan perintah, berdoa bersama, melakukan presensi, memperhatikan dan menyimak video, mengomentari video

Pada kegiatan pendahuluan guru mengajak siswa untuk melakukan doa bersama, hal ini dilakukan untuk menumbuhkan karakter religius siswa. Literasi yang muncul pada kegiatan pendahuluan tersebut adalah literasi budaya, baca tulis dan ICT. Selanjutnya, guru meminta siswa untuk presensi dan aktif berkomentar yang menumbuhkan karakter disiplin dan tanggung jawab pada siswa. Dalam pembelajaran ini literasi yang muncul adalah literasi ICT, baca tulis, numerik, dan sains,

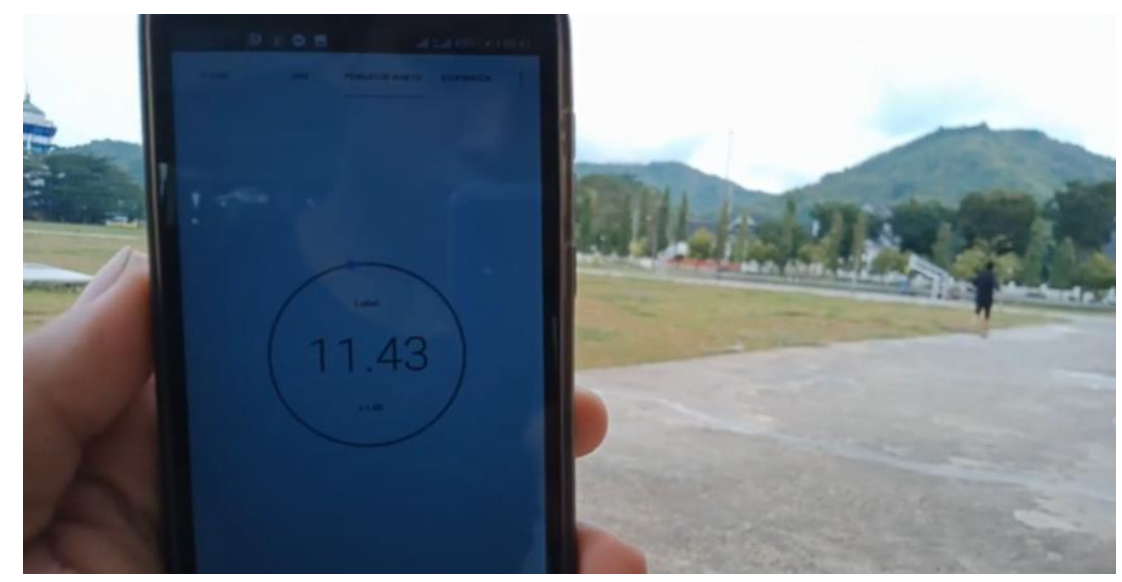

Gambar 3. Video Materi Pembukaan yang memunculkan literasi ICT, baca tulis, numerasi dan sains

Tabel 3. Langkah Kegiatan Pembelajaran (Bagian Inti)

\begin{tabular}{lllll}
\hline No & Jam & Isi & Keterangan & Literasi \\
\hline 1 & 09.17 & Aktifitas guru & lihat materi 15 menit. & TIC \\
2 & 09.25 & Sikap siswa; & "Baiklah buka dulu materinya ya, kalau ada & $I C T$ \\
& & keingin tahuan, & yang ditanyakan langsung ditanyakan aja & Baca tulis \\
& & inisiatif & mumpung tidak bayar" & Sains \\
3 & 09.36 & Aktifitas guru "Anak-anak silahkan buka link ini & ICT \\
& & Sikap siswa; & https://meet.google.com/yiy-sthi-rax kita & Sains
\end{tabular}


keingin tahuan, bermuwajjah ajah (itung-itung kenalan lagi) Numerik inisiatif pkl 09.45 ya di buka googlemeet nya" Baca tulis Guru berinteraksi dengan siswa.

Sikap siswa;
Disiplin,
tanggung
jawab

"Anak-anak silahkan dibuka, dibaca, ICT

$5 \quad 9.17-\quad$ Aktifitas siswa dipahami, dan kerjakan hal 77 (tabel 2.1) Baca tulis dan hal. 79 yang bawah ditunggu Sains jawabannya sampai pkl 10.30. numerik Tugas dikirim di Google Classroom". Menanggapi pertanyaan guru, bertanya, melaksanakan perintah guru, buka link, membaca, mengerjakan tugas, mengupload tugas

Pada kegiatan inti pembelajaran, guru meminta siswa untuk membuka materi yang berupa video dan meminta siswa untuk menanyakan hal - hal yang dirasa siswa kurang jelas melalui google meet. Pada kegiatan pembelajaran ini diharapkan dapat menumbuhkan rasa ingin tahu siswa dan juga inisiatif dari siswa, sementara literasi yang muncul pada kegiatan ini adalah literasi $I C T$, baca tulis dan sains. Kemudian siswa diminta untuk mengerjakan soal, dan diberikan batasan waktu pengumpulan untuk tugas tersebut, dengan begitu siswa akan memiliki tanggung jawab dan disiplin kerja. Literasi yang muncul dalam kegiatan ini adalah literasi $I C T$, baca tulis, sains dan menghitung.

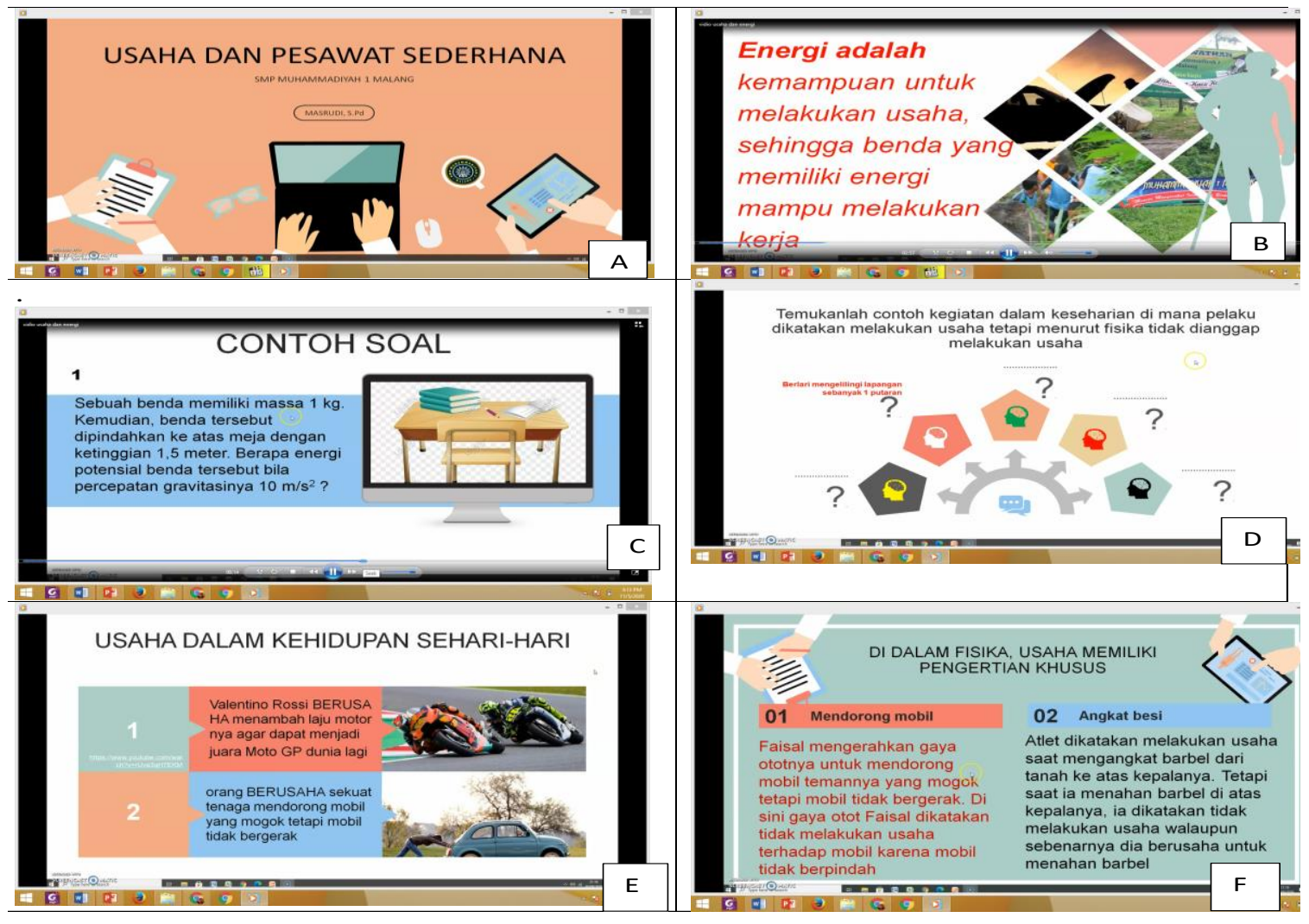

Gambar 4. Screenshot video materi pembelajaran usaha dan energi

Gambar 4A. Pembukaan materi yang memunculkan literasi digital (ICT)

Gambar 4B. Pembahasan materi energi yang memunculkan literasi digital (ICT) dan baca tulis

Gambar 4C. Contoh soal yang memunculkan literasi numerasi, digital (ICT), baca tulis, dan sains

Gambar 4D. Guru memberikan pertanyaan untuk memunculkan literasi sains, 
Gambar 4E.\&4F Pembahasan Materi beserta contoh dalam kehidupan sehari-hari memunculkan Literasi baca tulis, sains, numeric ICT.

Tabel 4. Pendampingan Kegiatan Pembelajaran (Bagian Penutup)

\begin{tabular}{|c|c|c|c|c|}
\hline No & Jam & Isi & Keterangan & Literasi \\
\hline 1. & 10.43 & $\begin{array}{l}\text { Aktifitas guru. } \\
\text { Sikap siswa : } \\
\text { Inisiatif, } \\
\text { keterampilan } \\
\text { sosial }\end{array}$ & $\begin{array}{l}\text { "Halo anak-anak demikian untuk pertemuan } \\
\text { kali ini ya, namun sebelumnya kalian harus } \\
\text { memberi pendapat dulu tentang kesimpulan hari } \\
\text { ini seperti berikut: } 1 \text {. usaha itu ........ 2. pada } \\
\text { kegiatan hari ini ...(menarik/kurang menarik)... } \\
\text { karena....... 3. sebaiknya untuk pertemuan } \\
\text { materi berikutnya adalah ......" }\end{array}$ & $\begin{array}{l}I C T \\
\text { Sains }\end{array}$ \\
\hline \multirow[t]{8}{*}{2} & $\begin{array}{l}10.48- \\
10.57\end{array}$ & $\begin{array}{l}\text { Aktifitas siswa } \\
\text { menyimpulkan }\end{array}$ & $\begin{array}{l}\text { Kesimpulan dan hasil refleksi Siswa } \\
\text { Raihan Rahman 10:48 AM } \\
\text { "Usaha atau kerja adalah energi yang } \\
\text { disalurkan gaya ke sebuah benda sehingga } \\
\text { benda tersebut bergerak" }\end{array}$ & $\begin{array}{l}\text { ICT } \\
\text { Sains, }\end{array}$ \\
\hline & & Aktifitas siswa & Darrel FBI10:52 AM & $I C T$ \\
\hline & & $\begin{array}{l}\text { Menyimpulkan } \\
\text { Refleksi }\end{array}$ & $\begin{array}{l}\text { "Ini kesimpulan pembelajaran hari ini } \\
\text { menururut saya pribadi. Harap anda makin siap } \\
\text { belajar esok hari. }\end{array}$ & $\begin{array}{l}\text { Sains, } \\
\text { Budaya } \\
\text { dan }\end{array}$ \\
\hline & & $\begin{array}{l}\text { Sikap siswa: } \\
\text { Inisiatif, } \\
\text { ketrampilan } \\
\text { sosial } \\
\text { Mandiri }\end{array}$ & $\begin{array}{l}\text { 1.usaha adalah suatu kegiatan yang diperlukan } \\
\text { sebuah benda untuk bergerak.Karena kalo } \\
\text { dibiarin ya tetep disana.Gak bakal gerak. } \\
\text { 2.pada kegiatan hari ini dirasa sudah } \\
\text { menarik. VC dari Pak Rudi membuat hati saya } \\
\text { tambah tentram.Karena ilmu yang anda share } \\
\text { udah saya pelajari sebelum di share. } \\
\text { 3.sebaiknya untuk pertemuan materi berikutnya } \\
\text { diharapkan kita kita semakin aktif dalam } \\
\text { berkomunikasi.Kita sama sama manusia,jangan } \\
\text { malu ataupun takut.Kalo orang tua juga takut } \\
\text { sih. Segitu aja kesimpulan pembelajaran hari ini } \\
\text { menurut saya.Harap kalian tetap pake masker } \\
\text { dan cuci tangan setelah bepergian". }\end{array}$ & $\begin{array}{l}\text { kewarga } \\
\text { an }\end{array}$ \\
\hline & & $\begin{array}{l}\text { Kegiatan siswa } \\
\text { menyimpulkan } \\
\text {, refleksi }\end{array}$ & $\begin{array}{l}\text { Almizan1710:54 AM } \\
\text { "1. Usaha adalah sejumlah gaya yg bekerja } \\
\text { pada suatu benda sehinggan menyebabkan } \\
\text { benda tersebut berpindah } \\
\text { 2. Menarik karena Pak Rudi yg ngajar } \\
\text { 3.Perpindahan gaya" }\end{array}$ & \\
\hline & & Kegiatan guru & "baiklah anak-anak kalian semua MEMANG & $I C T$ \\
\hline & & $\begin{array}{l}\text { Menutup } \\
\text { pelajaran }\end{array}$ & $\begin{array}{l}\text { LUARRRR BIASSSAAAH mari kita akhiri } \\
\text { pelajaran ini dan berdo'a di rumah masing- } \\
\text { masing jaga kesehatan dan selalu beribadah dan }\end{array}$ & $\begin{array}{l}\text { Sains, } \\
\text { Budaya } \\
\text { dan }\end{array}$ \\
\hline & & & $\begin{array}{l}\text { tetap SEMANGAT wassalaamualaikum wr } \\
\text { wb". }\end{array}$ & $\begin{array}{l}\text { kewarga } \\
\text { an }\end{array}$ \\
\hline
\end{tabular}

Pada kegiatan penutup guru meminta siswa untuk menyimpulkan dan memberikan pendapat atas kegiatan pembelajaran yang telah dilakukan, kegiatan ini diharapkan dapat membentuk sikap siswa yang memiliki inisiatif serta memiliki keterampilan sosial dan 
budaya. Literasi yang muncul dalam kegiatan ini adalah literasi ICT dan Sains, budaya dan kewargaan.

Kurikulum 2013 diharapkan akan dapat mengembangkan literasi bangsa melalui pembelajaran Bahasa Indonesia melalui pengembangan kemampuan membaca, menulis, dan berpikir kritis yang didukung pula oleh Gerakan Literasi Sekolah (Kusmana, 2017). Kemdikbud (2018a), pengembangan metode dan pengelolaan kelas dengan literasi bisa dilakukan pada semua mata pelajaran misalnya dengan menulis. Menulis dapat mengasah kepribadian atau budi pekerti seseorang. Inilah komponen yang sedang dibutuhkan bangsa ini sebagai bangsa yang multikulturalisme. Dalam merancang pembelajaran IPA terpadu, bermuatan PPK melalui literasi, dapat divariasikan beberapa literasi dasar. menurut Kemdikbud 2018b Literasi dasar yang perlu dijadikan poros pendidikan kita adalah (1) literasi baca-tulis, (2) literasi numerasi, (3) literasi sains, (4) literasi digital, (5) literasi finansial, serta (6) literasi budaya dan kewargaan. Dari kegiatan pembelajaran kelas VIII ini ada 5 literasi yang diperoleh yaitu literasi sains, ICT, Baca Tulis, numerik dan Literasi Budaya serta kewargaan. Literasi bacatulis merupakan pengetahuan dan kecakapan untuk membaca, menulis, mencari, menelusuri, mengolah dan memahami informasi untuk menganalisis, menanggapi, dan menggunakan teks tertulis untuk mencapai tujuan, mengembangkan pemahaman dan potensi, serta untuk berpartisipasi di lingkungan social (Saryono, 2017).

Numerasi dapat diartikan sebagai kemampuan untuk mengaplikasikan konsep bilangan dan keterampilan operasi hitung di dalam kehidupan sehari-hari (misalnya, di rumah, pekerjaan, dan partisipasi dalam kehidupan masyarakat dan sebagai warga negara) dan kemampuan untuk menginterpretasi informasi kuantitatif yang terdapat di sekeliling kita literasi numerasi bersifat kontekstual, sesuai dengan kondisi geografis, sosial budaya, dan sebagainya. (Weilin, Susanto, Dewayani, Pandora, Hanifah, Miftahussururi, Nento, \& Akbari, 2017). Pemecahan masalah, diskusi, penugasan Hal ini disebabkan karena literasi numerasi berkaitan dengan apresiasi dan pemahaman informasi yang dinyatakan secara matematis, misalnya grafik, bagan, dan tabel.

Makhrus, M (2012) menyatakan bahwa dalam pembelajaran IPA Terpadu, berisi keterkaitan materi fisika dengan kehidupan sehari-hari dan keterkaitan dengan materi biologi, ilustrasi gambar, penerapannya dalam kehidupan sehari-hari, mampu memberikan konstribusi bagi guru-guru SMP dalam rangka merancang kegiatan pembelajaran khususnya pembelajaran IPA terpadu. Rustaman (2007) berpendapat bahwa sains berperan dalam membangun karakter masyarakat dan bangsa dikarenakan kemajuan pengetahuan yang amat pesat, keampuhan proses yang dapat ditransfer pada bidang lain, dan terkandung muatan nilai dan sikap di dalamnya. Adapun literasi sains adalah bagaimana pemahaman tentang sains menjadikan solusi dalam pengambilan setiap keputusan yang dihadapi.

Literasi sains merupakan salah satu ketrampilan yang dapat dikembangkan dalam menghadapi era globalisasi, literasi sains dapat dimasukkan dalam kurikulum agar pembelajaran sains terutama IPA dapat meningkatkan pengetahuan terutama konsep-konsep ilmiah maupun teknologi (Astuti, 2017). Nasrullah (2017) menyatakan bahwa literasi digital lebih banyak dikaitkan dengan keterampilan teknis mengakses, merangkai, memahami, dan menyebarluaskan informasi. Sehingga bisa disebut juga sebagai literasi informasi. Menurut Muhajang dan Monica (2018) Literasi Informasi merupakan kunci utama dalam meningkatkan pengetahuan siswa. Dengan literasi informasi ini siswa akan mampu belajar secara mandiri, karena melibatkan mengenali kapan informasi diperlukan dan mampu efisien dalam mencari, akurat dalam mengevaluasi, secara efektif menggunakan, dan jelas 
mengkomunikasikan informasi dalam berbagai format. Dengan literasi digital ini bisa digunakan dengan strategi pembelajaran mandiri diantaranya pemberian tugas ataupun menggunakan E-Learning.

Literasi finansial adalah pengetahuan dan kecakapan untuk mengaplikasikan pemahaman tentang konsep dan risiko, keterampilan agar dapat membuat keputusan yang efektif dalam konteks finansial untuk meningkatkan kesejahteraan finansial, baik individu maupun sosial, dan dapat berpartisipasi dalam lingkungan masyarakat (Fianto, 2017). Literasi budaya dan kewargaan merupakan literasi kemampuan individu dan masyarakat dalam bersikap terhadap lingkungan sosialnya sebagai bagian dari suatu budaya dan bangsa. Prinsip dasar literasi ini adalah: (1) Budaya sebagai Alam Pikir melalui Bahasa dan Perilaku, (2) Kesenian sebagai Produk Budaya, (3) Kewargaan Multikultural dan Partisipatif, (4) Nasionalisme, (5) Inklusivitas, (6) Pengalaman Langsung (Hadiansyah, 2017).

Sebagai tindak lanjut dari kegiatan pembelajaran yang telah dilakukan, maka selanjutnya dilakukan Kegiatan refleksi pembelajaran kegiatan ini dilakukan guru, kepala sekolah, pendamping dosen, dan observer. Hasil kegiatan ini adalah bahwa kegiatan membuat RPP, pelaksanaan pembelajaran dapat dilaksanakan oleh guru. Namun belum semua guru dapat melaksanakannya dengan baik. Harapan selanjutnya, implementasi pembelajaran PPK melalui literasi dapat dilakukan secara kontinyu dan diimbaskan kepada guru-guru lainnya. Sebagai catatan, guru sudah dapat menyusun RPP karakter berbasis literasi namun pengembangannya masih ditemui beberapa kekurangan dan kelemahan. Berdasarkan kondisi ini, produk tersebut masih perlu terus diperbaiki, dikembangkan dan disempurnakan sehingga penerapannya di kelas menjadi lebih baik.

\section{KESIMPULAN}

Berdasarkan hasil Pelaksanaan Kegiatan Pengabdian Masyarakat di SMP Muhammadiyah 01 Kota Malang didapatkan kesimpulan sebagai berikut:

a. Meningkatnya wawasan dan kompetensi guru dalam menyusun RPP berbasis PPK melalui gerakan literasi.

b. Meningkatnya ketrampilan guru dalam melaksanakan pembelajaran di kelas sesuai Kurikulum 2013 yang menerapkan PPK melalui gerakan literasi lebih bervariasi meliputi literasi baca tulis, literasi numerik, literasi science, Literasi ICT dan Literasi Budaya.

\section{SARAN}

Berdasarkan serangkaian proses pelaksanaan pengabdian di SMP Muhammadiyah 01 Malang, maka dapat disarankan sebagai berikut.

a. Pengembangan RPP berbasis karakter melalui literasi, masih ditemui beberapa kekurangan dan kelemahan. Berdasarkan kondisi ini, produk tersebut masih perlu terus diperbaiki, dikembangkan dan disempurnakan sehingga penerapannya di kelas menjadi lebih baik.

b. Program ini perlu diimbaskan ke guru lain di lingkungan SMP Muhammadiyah Malang.

\section{UCAPAN TERIMAKASIH}

Ucapan terimakasih yang sebesar besarnya kami sampaikan kepada Direktorat Penelitian dan Pengabdian Masyarakat Universitas Muhammadiyah Malang yang telah membantu memberikan fasilitas dan pendanaan dalam kegiatan Pengabdian masyarakat ini. Terimakasih disampaikan kepada Kepala sekolah, guru-guru, karyawan dan seluruh warga sekolah SMP Muhammadiyah 01 Kota Malang yang telah bekerjasama dalam pelaksanaan kegiatan ini. 


\section{DAFTAR PUSTAKA}

Anonym, (2016) Ketrampilan Penting Abad 21 retrieved from https://rumahinspirasi.com/16keterampilan-penting-abad-21-yang-perlu-dipelajari-anak/

Astuti, Y. K. (2016). Literasi sains dalam pembelajaran ipa. Journal Universitas Wiralodra, $7(3 b), 67-72$.

Dewayani, S. (2017). Menghidupkan literasi di dalam kelas. Kanisius.

Dewayani, S. (2020). Menguatkan koneksi literasi rumah dan sekolah. Kanisius.

Kemdikbud. (2017). Mengapa perlu adnya pendidikan karakter. Depdikbud.

Fianto, F. (2017). Literasi finansial. Jakarta: Kementerian Pendidikan dan Kebudayaan.

Forum, W. E. (2016). The future of jobs. employment, skills and workforce strategy for the fourth industrial revolution. Global Challenge Indight Report.

Greenstein, L. (2012). Assessing 21st century skills:a guide to evaluating mastery and authentic learning. London: Sage Publications Ltd.

Hadiansyah, F. (2017). Literasi budaya dan kewarganegaraan. jakarta: Kementerian Pendidikan dan Kebudayaan.

Kebudayaan, Kementerian Pendidikan dan. (2016). Modul 1. implementasi literasi melalui pembelajaran, penguatan pendidikan karakter. Jakarta: Depdikbud.

Kebudayaan, Kementrian Pendidikan dan. (2016a). Kajian dan pedoman penguatan pendidikan karakter (ppk). Jakarta: Depdikbud.

Kebudayaan, Kementrian Pendidikan dan. (2016b). Modul penguatan pendidikan karakter. Jakarta: Depdikbud.

Kebudayaan, Kementrian Pendidikan dan. (2016c). Tiga pilar hadapi perubahan jaman. Jakarta: Depdikbud.

Kebudayaan, Kementrian Pendidikan dan. (2017a). Gerakan literasi nasional; materi pendukung literasi baca tulis. Jakarta: Depdikbud.

Kemdikbud. (2018a). Modul bimbingan teknis peningkatan kompetensi literasi bagi guru pendidikan dasar. Jakarta.

Kemdikbud. (2018b). Panduan praktis penguatan pendidikan karakter (PPK) berbasis kelas. Jakarta: Depdikbud.

Kusmana, S. (2017). Pengembangan Literasi Dalam Kurikulum Pendidikan Dasar Dan Menengah. Jurnal Pendidikan, Kebahasaan, Dan Kesusastraan Indonesia, 1(1), 151164. Retrieved from http://journal.um.ac.id/index.php/jptpp/article/view/8610

Mitasari, L. S., \& Utami, R. D. (2017). Peran kegiatan literasi dalam meningkatkan minat membaca dan menulis siswa kelas atas di SDN Gumpang 1. Univeristas Muhammadiyah Surakarta.

Makhrus, M., \& Hadiprayitno, G. (2012). Penerapan Perangkat Pembelajaran Fisika Berorientasi Pembelajaran IPA Terpadu Tipe Connected. Jurnal Pendidikan Dan Pembelajaran (JPP), 19(2), 237-242.

Muhajang, T., \& Pangestika, M. D. (2018). Pengaruh Literasi Informasi Terhadap Efektivitas Belajar Siswa. Pedagonal: Jurnal Ilmiah Pendidikan, 2(2), 15-22. https://doi.org/10.33751/pedagog.v2i2.849

Parmansyah, A., Endaryono, B. T., \& TjiptoDjuhartono. (2019). Penguatan Pendidikan Karakter Dalam. 6(1), 63-68.

Rustaman, D. (2017). Literasi baca tulis. Jakarta: Kementerian Pendidikan dan Kebudayaan.

Rustaman, N. Y. (2007). Kemampuan dasar bekerja ilmiah dalam pendidikan sains dan asesmennya. proceeding of the first international on science education. Bandung: Sps UPI.

Sugiyarti, L., Alrahmat, A., \& Mursalin. (2018). Pembelajaran abad 21 di SD Tema: menyonsong transformasi pendidikan abad 21. Jakarta: Prosiding Seminar dan DiskusiNasional Pendidikan Dasar.

Supiandi. (2016). Menumbuhkan Budaya Literasi. Menumbuhkan Budaya Literasi STUDIA, 
1(1), 93. Retrieved from http://www.paudni.kemdikbud.go.id/berita/8459.html,diakses

Suragangga, I. M. N. (2017). Mendidik lewat literasi untuk pendidikan berkualitas. Jurnal Penjaminan Mutu, 3. $\quad$ Retrieved from http://ejournal.ihdn.ac.id/index.php/JPM/article/view/195

Sutrisna, I., Sriwulan, S., \& Nugraha, V. (2019). Pengaruh Gerakan Literasi Dalam Meningkatkan Minat Baca Siswa. Parole (Jurnal Penddikan Bahasa Dan Sastra Indonesia), 2(4), 527. Retrieved from https://journal.ikipsiliwangi.ac.id/index.php/parole/article/view/2878

Wahyuni, S., Chamsiyatin, L., \& Zaenab, S. (2017). Percepatan penguatan pendidikan karakter di gerakan literasi smp muhammadiyah 02 kota batu. Laporan PMMI Universitas Muhammadiyah Malang.

Weilin, H., Susanto, D., Dewayani, S., Pandora, P., Hanifah, N., Miftahussururi, M., ... Akbari, Q. S. (2017). Materi pendukung literasi numerasi. Jakarta: Kementerian Pendidikan dan Kebudayaan.

Zaenab, S., Chamisijatin, L., \& Wahyuni, S. (2020). Strengthening character education through literacy movement at Muhammadiyah junior high schol. Journal of Community Service and Empowerment, 1(1), 54-63. https://doi.org/10.22219/jcse.v1i1.11516

Zubaidah, S. (2016). SitiZubaidah-STKIPSintang-10Des2016. Seminar Nasional Pendidikan, (2), 1-17. Retrieved from https://d1wqtxts1xzle7.cloudfront.net/55066726/SitiZubaidahSTKIPSintang-10Des2016.pdf?1511248452=\&response-content-

disposition=inline\%3B+filename\%3DSiti_Zubaidah_STKIPSintang_10Des2016.pdf\&E xpires $=1601649817 \&$ Signature $=I-p M \sim D P-I 4 r c K X 9$ shxejD3t7CpxSabpAZ-Ht 